\title{
Challenges Facing Women Academic Leadership in Secondary Schools of Irbid Educational Area
}

\author{
Mahmoud Khaled Mohammad Al-Jaradat ${ }^{1}$ \\ ${ }^{1}$ Faculty of Educational Sciences, Hashemite University, Zarqa, Jordan \\ Correspondence: Mahmoud Khaled Mohammad Al-Jaradat, Faculty of Educational Sciences, Hashemite \\ University, Zarqa, Jordan. Tel: 962-778-119-620. E-mail: mahmoudjrt@hotmail.com
}

Received: February 8, $2014 \quad$ Accepted: March 14, $2014 \quad$ Online Published: April 29, 2014

doi:10.5539/ies.v7n5p147 URL: http://dx.doi.org/10.5539/ies.v7n5p147

\begin{abstract}
This study aimed at identifying the challenges facing women academic leadership in secondary schools of Irbid Educational Area. A random sample of 187 female leaders were chosen. They responded to a 49-item questionnaire prepared by the researcher. The items were distributed into four domains: organizational, personal, social and physical challenges. The study concluded that the women academic leaders are facing challenges between medium and high levels. In addition, there is no difference attributed to the job position in all domains, except for the physical challenges in favor for the principals. There were differences attributed to the academic qualification in all the domains in favor of those who hold BA degrees or higher, except for the organizational challenges domain. Finally, there were no differences related to the years of experience in all domains. The study recommended setting up developmental programs for the women's academic leaders.
\end{abstract}

Keywords: challenges, leadership, women's leadership, schools, Irbid

\section{Introduction}

Several studies ascertained the woman's eligibility and her professional and leadership efficiency, which, sometimes, override that of the man. Yet, the occupational and leadership status of the woman is still suffering a wide gap, as there is unequal representation in the administrative and leadership positions between men and women, which became clear in many countries, particularly in Arab countries (Al-Shihabi \& Mohammad, 2001). Yang (1998) assured that the rate of women assuming higher leadership positions is not more than (3\%) in the United States and not more than 6\% in the United Kingdom. Hynowitz and Schellhardt (1986) further assure this, in what they termed the "Glass Ceiling", signaling the existence of barriers that prevent the advancing to higher leadership positions.

Women's leadership in educational institutions requires a humanitarian interaction process between all the parties to working in the enterprise, in addition to achieving inclusive institutional objectives. The woman faces many challenges that stand in the way of her success in leadership. In addition to the negative beliefs about the woman's leadership and her feminine nature, which creates the type of problems and difficulties preventing her progress and development in terms of administration and leadership (Al-Shaddi, 2010).

The idea of recognizing the challenges facing women's academic leadership in the secondary schools of Irbid Educational Area, Jordan, was formed because of some conferences held in the Arab countries about the woman and leadership. For instance, the Second Arab Woman Summit Conference held in Jordan in 2002, provided for: defining a strategy for the advancement of Arab woman; and giving her an effective role in the development of the community.

The first conference, held in the State of Kuwait in 2010 under the slogan "Women and the Renaissance of the Nation", also indicated that women have an effective role and wide participations in leading several community institutions to success, even though there are many pressures and obstacles standing in their ways for the continuity of the institutional work and assuming them leadership positions. Among the other concerns of the UNIFEM and UNICEF (2002) were eliminating all forms of prejudice and discrimination against women, especially in assuming administrative leaderships in community institutions, particularly the educational, in preservation of the woman's rights and her role in the inclusive development.

The issue of the woman, her education and role in the community institutions, particularly the educational, is still 
under study and interest of the literature and fields of thought by the writers and researchers in the leadership domain. Hill and Ragland (1995) examined treatment of the traditional barriers against the women's rising and taking charge of significant leadership positions in the different educational levels. Zanville (2001) was interested in analyzing women's personal characteristics, experiences and work location, and defined the challenges that face them in leadership. Al-Shaddi (2010) pointed out that the woman had a clear role in the management of educational institutions, especially the methods and approaches of managing the organizational struggles among them. Sernak (2003) focused on the cultural traits of the women's leadership in schools. Lynch (2003) distinguished between men and women in leadership in that men enjoy traits that help them in leading, such as self-sufficiency, decisiveness, power, self-assurance, domination, self-confidence, motivation, ability to compete, and discipline. On the other hand, women are characterized by qualities that showed their leadership abilities, through enhancing interaction between individuals, cooperation with others, focusing on social relations more than focusing on the hierarchy; and that the social relations style is the most common method among women's leadership. The study conducted by Dorn and Rouke (1996) showed that the most important traits of leaderships are: patience, positive thinking, enthusiasm, listening, organization, inclusiveness, care about all that is around them, acceptance of responsibility, and that they possessing the ability to contain those surrounding them.

Al-Hussein (2011) ascertained that women have distinct leadership traits and skills in leading educational institutions, even though they face certain difficulties and challenges that impede their leadership effectiveness. Jennifer (2008) indicated that women have the ability to balance between their work as a school leader and the family role in spite of all the various pressures. White's study (2012) also showed that there is a clear prejudice between men and women in assuming the administrative leadership position in favor of men, an indicative of marginalization of women's leadership roles. Meanwhile, Wilkinson (2009) found that the woman has a pioneer role in the academic circles. Brunner and Schumaker (1998) showed that the academic leadership in education is not limited to men rather than women, as the impact of gender on the individual behavior in leadership is worth being studied and paid attention to, due to its wide effect on work. The study further showed the women are characterized by leadership aspects that may not exist in men. Al-Minqash (2007) found that women had roles in leading and following-up academic works, and that there were no differences between the leading methods of women and men in the educational institutions, offering a further clear indication on the existence of the women's leadership role in different educational roles. Ali's (2003) study assured that there are no differences in the leadership effectiveness in the educational institutions between men and women.

Leadership is not a simple process; it requires multiple leadership abilities, whether assumed by men or women. In this concern, Meyerson and Joyce (2000) showed that leading others and dealing with them positively is one of the leadership success components; and that women's reach of advanced leadership positions is based on two bases: self-awareness and personality power, which leadership woman should possess. Rue and Byars (2003) indicated that leadership is the ability to influence the subordinates to accept orientations and adhere to the leader's decisions, based on the power stemming from organizational and personal resources, determined by the power the leader enjoys. Yukl (2002) further assured this view when he stated that the legal authority of the leader is among his/her power resources and his/her influence on the others. Al-Agha (2003) added that the self-power or personality is represented in the influence and specificity factor and admiration factor.

In this direction, Drew (2010), Al-Zuhair and Allaithi (2010), and Al-Douri et al. (2010) showed that, among other challenges the leader (both male and women) faces in education institutions, is the ability to employ the legal and personal power in the strategic leadership, innovation and ability to change, flexibility at work and dealing with others.

Chin, Lott, Rice, and Sanchez-Hucles (2007) ensured that the African-American women are facing social and environmental challenges that have impact on their leadership role, which mandates them to resort to the use of the law power in order to realize that role in educational institutions. The researcher sees that women's leadership in education lies in its difficulty and challenges, which can be attributed to intellectual, ideological dements of the leader and his/her personal traits, the nature of the individuals in terms of their abilities and their work roles expectations, as well as the nature of the attitude that leader and individuals are working toward achieving it.

All the above findings make those who deeply examine this issue fully understand the leading role of women, their problems in the community institutions, such as educational, and the importance of understanding the challenges that have impact on the women's leading role. In this concern, Jaber (2005) mentioned administrative, political, organizational, social and family challenges; Walter and Mimi (2002) and Al-Minqash (2007) indicated how to build an academic community and leading empowerment for the others. Hacıfazlığlu (2010) added 
some other challenges, such as adaptation to work environment, overcoming the internal and external pressures of the institution, achieving balance between her family role and leading role in the institution, and finally low levels of achieving good relations with others. Monty (2012) found that women are facing societal and familial challenges, such as distinction between masculine and feminine leaderships, poor support of women's leadership idea, and lack of confidence and leading ambition. Finally, Holter and Frabutt (2012) added the contemporary challenges of employment of information technology and knowledge in the leadership.

A number of writers, researchers and advocates of the women's leadership summarized the challenges facing women's leading roles in the educational institutions as follows:

- Organizational challenges: factors related to the administrative organization that may hinder the academic leadership to achieve the objectives of the institution (Al-Minqash, 2007; Abu Khdair, 2012).

- Under-empowerment challenges: factors that limit the ability of the academic leadership to affect, taking the right decisions, and eliciting the change required to realize success and distinct in performing her leadership role (Abu-Khdair, 2012; Al-Kubaisi, 2004).

- Cultural challenges: a number of prevailing cultural concepts and beliefs concerning the view of women as leaders, whether in the eyes of her men colleagues, her subordinates or women colleagues as well (Abu-Khdair, 2012).

- Self-challenges: including personal factors and characteristics that have negative effects on practicing her leadership role successfully (Al-Shihabi, 2008).

- Physical and technical challenges: including the other obstructions related to the physical work environment, and technical supplies that limit the ability of the women leader to achieve the objects assumed to her (Al-Minqash, 2007).

Of the results of these studies, there were indications to the multiple challenges facing the woman in her leadership of the educational institutions. Kamfer's study (1998) showed that among the challenges are denying the women's leadership decision taking powers, limiting the existing communication means, low confidence in decision making, and centrality in decision taking. In contrast, Zulu's study (2011) found that the woman, in her leadership, is characterized by strong communications and dealing skills with others, abilities to possess the information and share power, as well as her participatory style of work. On the other hand, Jaber's study (2005) showed that the challenges facing the Palestinian woman's leadership in the educational institutions are legal, political, social, familial and administrative challenges; and that there are statistically significant differences among the evaluations of the study sample attributed to the years of experience variable. Meanwhile a study by Al-Raqeb (2009) indicated that most of the challenges facing the woman's leadership role are social, followed by political, and personal. The study did not find differences among the sample members attributed to the years of experience variable. Still, a study by Al-Hussein (2011) found that the leading woman in the Ministry of Education in Jordan faces some challenges to reach the leadership positions, most important are: the negative stereotype of the woman in the mind of both the males and women; the women's limited ambitions, lack of confidence in herself and her abilities, and discontinuity in her work. Abu-Khdair (2012) arranged the most important challenges facing the women academic leaderships in the educational institutions of the Kingdom of Saudi Arabia as follows: organizational, technical, lack of empowerment, cultural and self-challenges, respectively. The study conducted by Becks (2004) concluded that leadership challenges facing the African-American women in education are balanced between the house and work responsibilities, ethnicity, gender, low respect levels of their colleagues, under-representation of the woman at work, and lack of the confidence of both the workers and community in the woman's leadership. The study of Burns and Martin (2010) found that women's leadership at schools is facing the challenges of poor confidence and respect as compared by that of the man's leadership. Finally, the study of Bloom and Erlansdon (2003) explored, through personal interviews program with a number of African-American women's leaderships, how they surpassed some challenges such as lack of trust in their leadership and job satisfaction which were barriers in the way of their effective leaderships at schools.

\section{Objective of the Study}

The study aims at identifying the challenges facing women academic leaderships in women secondary schools of Irbid Educational Area, Jordan, through four dimensions: organizational, personal, social and physical; and by the results of the evaluations of a sample of the women school principals and assistants as educational leaders. Specifically, the study was designed to answer the following research questions: 
i. What are the challenges facing the women academic leadership in the secondary girls' schools of Irbid Educational Area?

ii. Are there statistically significant differences at $(\alpha \leq 0.05)$ level among the study sample members on the challenges facing the women academic leaderships by the job title, academic degree and years of experience variables?

\section{Significance of the Study}

The importance of this study arises from the significance of the role of women's academic leaderships in driving the advancement and development wheels in their domains, functions, and major processes, as well as facing the challenges, difficulties, and abrupt changes that the future may carry.

The results of this study may be directed to decision makers to determine the educational policies, to underline the required change aspects and modernization in the educational work, leadership methods and demands, toward achieving the desired educational objectives. In addition, the study results will be a starting point for future research work that links the leading role of the woman to society institutions and its difference sectors.

\section{Method}

The researcher selected the descriptive, analytic method, due to its suitability to the research nature, and feasibility of realizing its objectives to describe and analyze the responses of the study sample members about the challenges facing the women academic leaderships.

\subsection{Population and Sample}

The study sample consisted of all women academic leaders (principals and assistants) of Irbid Educational Area. The total study population was brought up to 302 members. A random sample of 187 women leaders was chosen forming $62 \%$ of the total study population. Table 1 illustrates this.

Table 1. Distribution of the study sample by their variables at Irbid Educational Area/1

\begin{tabular}{ccccc}
\hline & Variables & Study Population & Study Sample & $\begin{array}{c}\text { Ratio of the Sample to } \\
\text { the Total Population }\end{array}$ \\
\cline { 2 - 4 } Job Title & Number & Number & \\
& Principal & 146 & 102 & $70 \%$ \\
\cline { 2 - 4 } & Assistant Principal & 156 & 85 & $54 \%$ \\
\hline \multirow{2}{*}{$\begin{array}{c}\text { Academic } \\
\text { Degree }\end{array}$} & BA & 173 & 114 & $66 \%$ \\
\cline { 2 - 4 } $\begin{array}{c}\text { Work } \\
\text { Experience }\end{array}$ & MA or higher & 129 & 73 & $56 \%$ \\
\cline { 2 - 4 } & Less than 5 years & 67 & 29 & $43 \%$ \\
\cline { 2 - 4 } & 5-10 years & 130 & 82 & $63 \%$ \\
\hline Total & More than 10 years & 105 & 76 & $72 \%$ \\
\hline
\end{tabular}

\subsection{Instrument}

Based on the methodology of the current study, the researcher developed the study instrument (questionnaire) for the aim of defining the challenges facing the women academic leaders in Irbid Educational Area. In constructing the questionnaire, the researcher observed the following:

- Review of the theoretical literature related to the study topic.

- Assigning the instrument domains, which are four domains, containing the challenges facing the women academic leaderships; namely: organizational, personal, social and physical challenges.

- Fifty-five items were paraphrased and distributed over the study domains as follows: organizational challenges (16); personal challenges (14); social challenges (10), and physical challenges (15).

- Making the measurement instrument with its final form after carrying out the validity and reliability processes. 
- All the items were organized for responses by the study sample members based on Likert's five grading points scale as follows: very high, high, medium, low, and very low, which were given the following values: 5, 4, 3, 2 and 1, respectively. Assessment degree on the open categories was obtained by calculating the difference between the highest and lowest degrees, and the difference was (4). Dividing this difference by (5), the category length obtained was $(0.80)$. Accordingly, the means of the evaluation of the study sample members to the questionnaire items were as follows: (4.21-5): very high, (3.414.20): high, (2.61-3.40): medium, (1.81-2.60): low, and (1-1.80) very low.

\subsubsection{Validity of the Instrument}

The study items were presented to a number of specialized and experienced arbitrators $(n=30)$, professionally specialized in education and educational leadership. The researcher requested them to examine the relatedness extent of the item to the domain or dimension that it measures. Their remarks and comments about the study items and domains were taken into account.

As a result of these procedures, the final number of the items was determined at 41 items measuring the degrees of the challenges facing the women's leaderships at the secondary girls' schools of Irbid, distributed over the following challenges: organizational challenges: (11), personal challenges: (11), social challenges: (8), and physical challenges 11 items.

To reassure the validity of the instrument, the researcher applied it on an exploratory sample consisted of 20 women leaders. The correlation coefficient between each item and the domain it belongs to, and the correlation coefficients of the items to the domains were as follows: the social challenges domain ranged between 0.46-0.92; the personal challenges $(0.58-0.94)$; the social challenges $(0.55-0.94)$, and the self-challenges domain between (0.57-0.92); all of which were at $(\alpha \leq 0.05)$ significance level.

The researcher also calculated the validity of the internal consistency and its correlation to the instrument as a whole, as per Pearson correlation coefficient. The results were as follows: correlation coefficient of the organizational challenges was $(0.93)$; personal challenges $(0.91)$; social challenges $(0.89)$, and self challenges correlation coefficient was (0.98), all indicative of the validity of the items and domains as well as measurement of the trait it was assigned to measure.

\subsubsection{Reliability of the Study Instrument}

The researcher applied the study instrument to a sample consisted of (20) members of the study population to ensure the reliability of the instrument, employing Chronbach Alpha coefficient. The results showed that the reliability coefficients of the different domains were as follows: organizational challenges (0.96); personal challenges (0.95); social challenges (0.90); and physical challenges (0.93). Furthermore, the total reliability coefficient was (0.95) meaning that the instrument with its domains is fit for the study objectives.

\subsection{Variables of the Study}

The study includes one dependent variable, i.e. the challenges facing the women academic leaderships, and three independent variables, i.e. job title (two categories: women school principal, assistant principal); academic degree (two categories: BA, MA and higher); and years of experience (three categories: less than 5 years, 5-10 years and more than 10 years).

\subsection{Statistical Analyses}

Pearson correlation coefficient and alpha Chronbach correlation coefficient were used to realize the validity and reliability of the study tool. Furthermore, the researcher employed the one-way variance (ANOVA) analysis method, as well as T-Test to determine the differences among the response of the study sample according to its variables, all after entering the data to the Statistical Program of the Social Studies (SPSS).

\section{Results}

Results of the first question: What are the challenges facing the women academic leaderships in the secondary girls' schools of Irbid Educational Area?

The means (M's) and standard deviations (SD's) and the percentage of each and every item of the four domains were arranged in a descending order by their M's and percentages. The results are summarized and shown in Table 2, which indicates that the physical challenges accounted for the highest mean 3.67 and $73.4 \%$; followed by the organizational challenges with 3.42 mean and $68.4 \%$, with both domains are representative of the high degrees of challenges facing the women leaders. And the lowest degrees were in the social challenges with 3.25 mean and $65.0 \%$; followed by the personal challenges with 3.31 mean and $66.2 \%$. These latter domains represent the medium degree in challenges. The overall results showed that the challenge degree represent a high degree 
with an overall mean 3.42 and a $68.4 \%$ for all the domains.

Results of the second question: Are there statistically significant differences at $(\alpha=0.05)$ level among the study sample members on the challenges facing the women's academic leaderships by the job title, academic degree and years of experience variables?

To answer this question, the means and standard deviations were calculated as well as the one-way ANOVA analysis, and T-Test of the responses of the study sample members, as per every variable of the study. The results of this question will be illustrated as follows.

\subsection{By Job Title Variable}

Based on the results shown in Table 3, there are no statistically significant differences at $(\alpha-0.05)$ significance level in each of the domains, and at the domains as a whole, except for the physical challenges domain, for which the results showed statistically significant differences at $(\alpha-0.05)$ significance level, in favor of the male school principals, as per the comparison of the M's.

\subsection{By Academic Degree}

Based on the M's, SD's and T-Test, shown in Table 4, results indicate that there are no statistically significant differences at $(\alpha-0.05)$ significance level in the organizational challenges domain, and domains as a whole. The results further showed statistically significant differences in the personal, social and physical domains, in favor of those holding MA degrees or higher, as per the comparison of the means.

\subsection{By Work Experience}

Based on the results of the ANOVA analysis duly shown in Table 5, the results showed no statistically significant differences at $(\alpha-0.05)$ significance level in any domain and the level of the domains as a whole.

Table 2. Means and percentages of the responses of the study sample members to the challenge domains facing the women leaders, by each domain and the total domains level

\begin{tabular}{llccccc}
\hline $\begin{array}{l}\text { Domain } \\
\text { Order }\end{array}$ & Domains & $\begin{array}{c}\text { Mean By } \\
\text { Degree }\end{array}$ & $\begin{array}{c}\text { No. of } \\
\text { Items }\end{array}$ & $\begin{array}{c}\text { Mean By } \\
\text { Response }\end{array}$ & Percentage & $\begin{array}{c}\text { Challenge } \\
\text { Degree }\end{array}$ \\
\hline 1 & Physical Challenges & 40.41 & 11 & 3.67 & $73.4 \%$ & High \\
\hline 2 & Organizational Challenges & 37.58 & 11 & 3.42 & $68.4 \%$ & High \\
\hline 3 & Personal Challenges & 36.40 & 11 & 3.31 & $66.2 \%$ & Medium \\
\hline 4 & Social Challenges & 26.03 & 8 & 3.25 & $65.0 \%$ & Medium \\
\hline & Total & 140.42 & 41 & 3.42 & $68.4 \%$ & High \\
\hline
\end{tabular}

Table 3. Means and results of T-Test of the responses of the study sample members of the challenges domains facing the women academic leaderships by the job title variable

\begin{tabular}{|c|c|c|c|c|c|c|}
\hline Domains & Job Title Variable & No. & M & SD & $\mathrm{t}$ & Sig. \\
\hline \multirow{2}{*}{$\begin{array}{c}\text { Organizational } \\
\text { Challenges }\end{array}$} & Principal & 102 & 36.4314 & 9.99258 & \multirow{2}{*}{-1.799} & \multirow{2}{*}{0.074} \\
\hline & Asst. Principal & 85 & 38.9647 & 9.07960 & & \\
\hline \multirow{2}{*}{ Personal Challenges } & Principal & 102 & 37.5000 & 10.54246 & \multirow{2}{*}{1.790} & \multirow{2}{*}{0.075} \\
\hline & Asst. Principal & 85 & 35.0824 & 7.24932 & & \\
\hline \multirow{2}{*}{ Social Challenges } & Principal & 102 & 26.6667 & 7.89076 & \multirow{2}{*}{1.363} & \multirow{2}{*}{0.174} \\
\hline & Asst. Principal & 85 & 25.2707 & 5.67658 & & \\
\hline \multirow{2}{*}{ Physical Challenges } & Principal & 102 & 42.0686 & 10.72912 & \multirow{2}{*}{2.705} & \multirow{2}{*}{$* 0.007$} \\
\hline & Asst. Principal & 85 & 38.4353 & 6.77258 & & \\
\hline \multirow{2}{*}{ Total Domains } & Principal & 102 & 142.6667 & 28.18374 & \multirow{2}{*}{1.242} & \multirow{2}{*}{0.216} \\
\hline & Asst. Principal & 85 & 137.7529 & 25.35177 & & \\
\hline
\end{tabular}

\footnotetext{
* Sig. at $(\alpha=0.05)$.
} 
Table 4. Means and results of T-Test of the responses of the study sample members of the challenges domains facing the women academic leaderships by the academic degree variable

\begin{tabular}{|c|c|c|c|c|c|c|}
\hline Domains & Job Title Variable & No. & $\mathrm{M}$ & SD & $\mathrm{t}$ & Sig. \\
\hline \multirow{2}{*}{$\begin{array}{l}\text { Organizational } \\
\text { Challenges }\end{array}$} & $\mathrm{BA}$ & 114 & 38.7808 & 9.25600 & \multirow[t]{2}{*}{-1.362} & \multirow[t]{2}{*}{0.175} \\
\hline & MA or Higher & 73 & 36.8158 & 9.85161 & & \\
\hline \multirow[t]{2}{*}{ Personal Challenges } & $\mathrm{BA}$ & 114 & 34.6575 & 7.29197 & \multirow[t]{2}{*}{2.081} & \multirow[t]{2}{*}{$* 0.039$} \\
\hline & MA or Higher & 73 & 37.5175 & 10.18348 & & \\
\hline \multirow[t]{2}{*}{ Social Challenges } & BA & 114 & 24.7531 & 5.73435 & \multirow[t]{2}{*}{2.018} & \multirow[t]{2}{*}{$* 0.045$} \\
\hline & MA or Higher & 73 & 26.8509 & 7.59743 & & \\
\hline \multirow[t]{2}{*}{ Physical Challenges } & $\mathrm{BA}$ & 114 & 38.3151 & 6.79231 & \multirow[t]{2}{*}{2.508} & \multirow[t]{2}{*}{$* 0.013$} \\
\hline & MA or Higher & 73 & 41.7632 & 10.40788 & & \\
\hline \multirow[t]{2}{*}{ Total Domains } & BA & 114 & 136.5068 & 25.80327 & \multirow[t]{2}{*}{1.599} & \multirow[t]{2}{*}{0.111} \\
\hline & MA or Higher & 73 & 142.9474 & 27.51503 & & \\
\hline
\end{tabular}

* Sig. at $(\alpha=0.05)$.

Table 5. Means and results of One Way ANOVA of the responses of the study sample members of the challenges domains facing the women academic leaderships by the academic degree variable

\begin{tabular}{|c|c|c|c|c|c|c|}
\hline Domains & Variance Source & Total Squares & $\begin{array}{l}\text { Freedom } \\
\text { Degree }\end{array}$ & $\begin{array}{l}\text { Square } \\
\text { Mean }\end{array}$ & F Value & Sig. \\
\hline \multirow{3}{*}{$\begin{array}{l}\text { Organizational } \\
\text { Challenges }\end{array}$} & Between Groups & 439.022 & 2 & 219.511 & \multirow[t]{3}{*}{2.394} & \multirow[t]{3}{*}{0.094} \\
\hline & Within Groups & 16868.443 & 184 & 91.676 & & \\
\hline & Total & 17307.465 & 186 & & & \\
\hline \multirow{3}{*}{$\begin{array}{l}\text { Personal } \\
\text { Challenges }\end{array}$} & Between Groups & 1.806 & 2 & 0.903 & \multirow[t]{3}{*}{0.10} & \multirow[t]{3}{*}{0.990} \\
\hline & Within Groups & 15909.114 & 184 & 86.463 & & \\
\hline & Total & 15910.920 & 186 & & & \\
\hline \multirow[t]{3}{*}{ Social Challenges } & Between Groups & 61.333 & 2 & 30.667 & \multirow[t]{3}{*}{0.62} & \multirow[t]{3}{*}{0.536} \\
\hline & Within Groups & 9024.474 & 184 & 49.046 & & \\
\hline & Total & 9085.807 & 186 & & & \\
\hline \multirow{3}{*}{$\begin{array}{l}\text { Physical } \\
\text { Challenges }\end{array}$} & Between Groups & 49.251 & 2 & 24.625 & \multirow[t]{3}{*}{0.28} & \multirow[t]{3}{*}{0.754} \\
\hline & Within Groups & 16042.215 & 184 & 87.186 & & \\
\hline & Total & 16091.465 & 186 & & & \\
\hline \multirow[t]{3}{*}{ Total Domains } & Between Groups & 626.894 & 2 & 313.447 & \multirow[t]{3}{*}{0.42} & \multirow[t]{3}{*}{0.652} \\
\hline & Within Groups & 134707.021 & 184 & 732.103 & & \\
\hline & Total & 135333.914 & 186 & & & \\
\hline
\end{tabular}

\section{Discussion}

The study focused on exploring the challenges facing the women academic leaderships as a means to determine the ways and methods as well as propose the suitable programs to overcome these challenges. The first question was about identifying the challenges that face the women's leaderships in schools, employing the responses of 
the study sample members to the items of the organizational, personal, social and physical domains. For the purpose of processing the data to answer this question, the researcher used the means and percentages depending on Likert five-point scale as follows: very high, high, medium, low, and very low, with the values: $5,4,3$,2, and 1 , respectively.

Results shown in Table 2 showed that the total mean of all the items of the study domains was 3.42 and $68.4 \%$ representing the high degree. The highest challenges facing the leader woman were the physical challenges with 3.67 mean and $73.4 \%$, also accounting for the high degree; followed by the organizational challenges with 3.25 mean and $68.4 \%$. On the other hand, the lowest challenges were the personal with 3.25 mean and $65 \%$ representing the medium degree, and the social challenges with 3.31 mean, $66.2 \%$ and medium degree.

This result indicates two dimensions. First, the physical aspects are closely related to the organizational aspects, as the physical aspect supports the organizational one in the work of the women leaders to achieve the school objectives. Thus, both domains accounted for high degree of challenge. Second, the social and personal challenges are interlocking in terms of the impact of the women's leadership on them.

As a result, the researcher views the lack of the required supplies for the educational process such as laboratories and technologies an obstacle in the way of the women's leadership at schools. This is directly reflected on the lower organizational level needed to serve the educational and teaching objectives in schools. In addition, the emergence of the problem with the physical aspects leads to the weakness of the innovation and creativity processes with the women leaders. Furthermore, they will not be able to keep up with the technical developments characteristic of the current age, as well as wasting the chance of time investing for achieving the leading and organizational work assignments. This result is consistent with that of Abu-Khdair (2012), which assured that among the challenges facing the women leaders are physical with vast impact at the level of the institutional organization process. The fact that the organizational challenges are the most challenges facing the women leaders had gained the second order among the other challenges, is attributed to the lack of constant legal controls to which the leadership should report in order to control the work. It is also attributed to the centrality of the decision taking, which will lead to consecutive pressures on the women's leadership role, and scarcity of the innovative and creative initiatives needed for the institutional work. This was further supported by the study of Jaber (2005), which found that the organizational challenges are the most often facing the women's leadership, followed by the legal and political challenges.

The reasons for the personal and social challenges of the women's leaderships in schools may be ascribed to many factors such as: lack of women's leadership perception to the self-development process about modern leadership, as well as non-matching between her work as a leader and her familial role, which, in turn, would prevent her attending leadership-focused training courses. In this direction, Bloom and Erlandson (2003) reassured that training process is vital for re-qualification of women's leadership. Another reason is that the woman's emotions are widely reflected on her leadership style. White's study (2011) indicated that the women's leadership is characterized by leniency, application of emotional methods without bearing on personality strength These results are consistent with those of the studies of Becks (2004) and Al-Shaddi (2010), which both found that, among the challenges facing women's leadership in schools, personal challenges are emerging from the woman's abilities and nature. The researcher also explained the reasons for the social challenges against the woman's leadership, attributing them to the community cultural dimension, with its inferior view of the woman being of a leading status, and that she will be weak in her leadership.

This view finds support in the study conducted by Becks (2004) which results pointed out to the women poor representation in work as well as the negative culture of the community toward women's leadership. This result is also in line with those of Abu-Khdair's (2012) study which indicated that the challenges facing leader woman in the educational institutions were social and cultural. The results of this study question are in line with those of Al-Hussein (2011), which further showed that the leader woman was facing certain challenges in her way to approach the leading positions, such as: the negative stereotype of the woman in both the men and women mind; limited ambitions; lack of confidence in herself and her abilities; interruptions of her work; and favoritism against her. These results are also consistent with those of Al-Raqab (2009) study which illustrate that the most challenges expressed by the study sample were: social challenges, followed by political challenges and finally personal challenges.

As for the second question of the study, it aimed at identifying the differences between the evaluations of the study sample individuals of women leaders about the challenges facing women leaders by the job title, academic degree and years of experience.

Depending on the means and results of T-Test, shown in Table 3, the results did not exhibit differences among 
the responses of the women leaders by the job title variable (principal, assistant principal), on each and every domain, and the level of the domains as a whole. Meanwhile, there were differences in the physical challenges domain, in favor of the male principals, as per the comparison of the means.

The researcher interprets this result through the factuality in which the women's leadership is working, in terms of rules and systems applicable in schools. In addition to the nature of the environment and community culture concerning assuming women leadership positions. This made the evaluations of the study sample members very close, without wide variance. Meanwhile, the variance was clear in the physical challenges, which may be explained by the fact that the weakness of the supplies and work requirements, which serve achieving an educational, teaching environment, are touched more by the principals than by the assistant principals, on the grounds that the principal is the person accountable before the higher administrative leaderships. This result is quite in line with that of Al-Raqeb (2009) and Al-Shaddi (2010), both showing differences by the job title variable. Yet, it is not consistent with that of Jaber (2005) which showed statistically significant differences among the responses means of the study sample members.

The results further showed statistically significant differences in each of the personal, social and physical challenges and in the level of the domains as a whole, depending on the values of the means and the results of the T-Test duly illustrated in Table (4), built on the academic degree variable (BA, MA and higher), in favor of the women leaders holding MA and higher, i.e. not in line with the study of Al-Minqash (2007). The results also did not show differences in the organizational challenges domain, which is in line with those of Al-Minqash (2007), and Jaber (2005). The researcher, again, interprets this due to the fact that the organizational side is most often linked to firm bases, rules and regulations, connected to the higher educational management. On the other hand, the personal and social aspects are more linked to the leader him/herself, as will his/her acceptance of the situation in which work is done, in the light of the community nature and culture. Furthermore, the physical aspects may be provided and prepared in compliance with the existing capabilities.

The results also indicated, through ANOVA values shown in Table 5, that there were no differences in the evaluations of the study sample individuals in each and every challenge domain (organizational, personal, social and physical), and in the level of the domains as a whole. This result may be ascribed to the workers views, in any field, that with their different experiences they are able to identify the phenomena, events and conditions that the organization lives. This made the evaluations of the sample members about the challenges close to each other without clear variance. This result, again, is in agreement with those of Al-Minqash (2007) and Al-Shaddi (2010).

\section{Conclusion}

In conclusion, the researcher found many challenges faced by the women's leadership in schools, which were identified through the measuring instrument prepared by the researcher, which was subjected to the validity and reliability procedures, to ensure its validity and suitability to the study topic. It was applied on a sample consisting of 187 leaders in schools, and its resulted indicated that the most challenges these women leaders faced were: physical challenges, directly followed by the organizational challenges. On the other hand, they face, with medium levels, personal and social challenges.

This calls for the need to take suitable developmental procedures by the education policy in the area, to encourage the leading role of the woman in the educational institutions and their various levels, whether at the school level or higher levels. This could be achieved through: availing opportunities before the leaderships to join training courses in the field of leadership; applying clear organizational bases by the higher educational administration; supporting women's leading positions in educational institutions, particularly in schools; and work for meeting the physical needs that help the woman in preparing the suitable teaching environment. This will be reflected in the quality of organization and leading work of the women, based on that the organizational and physical aspects are the major challenges facing the leader woman in schools.

Some challenges concerning the personal and social aspects the woman is suffering from should be eliminated through conducting interviews with the women's academic leadership, in order to encourage their leading role, and not to pay any attention to the social vision against them, as well as the negative view that they have weak personal abilities. This may be applied as an experiment that proved successful in the study conducted by Bloom and Erlandson (2003), in which they conducted personal interviews with a number of the African-American women leaders, in order to surpass certain challenges such as: lack of confidence and job satisfaction, which were standing as stumble stones in the way of their effective leadership in the schools.

Due to the importance of the woman's role in the community, in general, and in the educational institutions, in particular, many studies had been conducted all over the world, and some Arab countries, about the woman and 
her different roles. Thus, this study is distinguished from other studies by being applied on the women's leadership levels in the schools.

The researcher hopes that the results of this study will be presented before decision makers/takers at higher education administrations, in order to provide programs that enhance the leading role of the woman in schools, and consider the study recommendations, for overcoming the challenges the women are facing.

\section{Recommendations}

In the light of the study literature and field results, several recommendations could be formed as follows:

- Providing required supplies and appliances for the work requirements in schools in order to enhance and overcome the problems of the physical aspect of the women's leadership at schools.

- Availing chances for women's academic leaderships to join training courses about how to solve work problems and mechanisms for approaching suitable solutions, and methods for decisions taken based on delicate and accurate studies and information.

- Orientating women's academic leaderships to the scientific research methods to enable conducting studies about the gaps and work pressures for setting the scientific solutions thereof.

- Opening the door before the women's leaderships at schools to participate in the decision-taking process and setting the organizational bases that boost the leading role of the women at schools.

- Introducing the principle of specialization and higher education degree as a base for women to assume the leadership position at school.

\section{Suggested Scientific Studies}

As a result of the accumulated experience and knowledge of the researcher throughout the study course, and the challenges he had touched directly, which were and are facing the women's academic leaderships, he suggests the following topics be the focus of the future researchers seeking research in this subject:

- Conducting a study about the adaptation strategy to the work pressures on the women's academic leaderships at schools.

- Extent of the women's academic leadership possession of administrative, leading efficiencies, in order to practice their administrative and technical assignments at schools.

- Conducting a study about the cooperation and integration between the higher education leadership and school leadership.

\section{References}

Abu-Khader, S. (2012). Challenges facing the women's academic leaderships in the higher education institutions in Kingdom of Saudi Arabia. Saudi Higher Education Journal, 3(7).

Al-Agha, W. (2003). Role of the Administrative Leaderships in the Administrative Development. The Fourth Annual General Conference on Management, 12-16 October, Damascus.

Al-Douri, Z. et al. (2010). Management principles and entrances and their functions (1st ed.). Amman: Al-Yazouri Scientific Publishing and Distribution House.

Al-Hussein, E. B. (2011). Traits and skills characterizing the Jordanian leader woman and obstacles facing her. Damascus University Journal, 27(3, 4).

Ali, I. (2003). Woman and the administrative leadership styles. The fourth Annual General Conference on Administration: Creative Leadership to Develop the Institutions in the Arab World, held in Damascus, 13-16 October.

Al-Kubaisi, A. K. (2004). Knowledge management and organizations development. Alexandria: Modern University Office.

Al-Minqash, S. A. (2007). Leadership over the group leadership with the group: A comparative study between the two male and women leadership styles at King Saud University. Education and Psychology Mission Magazine, 28, 34-45.

Al-Raqeb, M. S. (2009). Obstacles of the woman's practices of the leadership behavior in the higher education institutions in Gaza Strip, and methods to overcome them (Unpublished Master thesis, the Islamic University, Gaza).

Al-Shaddi, A. M. (2010). Conflict management at the women's leadership in the higher education institutions in 
the Riyadh City (Unpublished Master thesis, Princess Noura Bint Abdel Rahman University, Kingdom of Saudi Arabia).

Al-Shihabi, E. (2008). Methods for activating the administrative Arab woman's role. A Research Presented to the Forum of Role of the Arab Woman in the Sustainable Development and the Civil Society Institutions, Doha-Qatar.

Al-Shihabi, E., \& Mohammad, M. (2001). Woman predicative problems of the leading position as viewed by the women leaderships. Creative Leadership Conference on Facing the Contemporary Challenges of the Arab Management, The Arab Administrative Development Organization, Cairo, 5-8/11/2001.

Al-Zuhairi, I., \& Al-Laithi, R. (2010). The educational management and school management in the twenty-first century (1st ed.). Hael, Kingdom of Saudi Arabia: Al-Andalus Publishing and Distribution House.

Becks, G. M. (2004). African American women administrators in higher education: Exploring the challenges and experiences at Louisiana public colleges and universities (Unpublished doctoral dissertation, Louisiana State University, Louisiana).

Bloom, C. M., \& Erlandson, D. A. (2003). African American Women principals in urban schools: Realities, reconstructions, and resolutions. Educational Administration Quarterly, 39(3), 339-369. http://dx.doi.org/10.1177/0013161X03253413

Brunner, C., \& Schumaker, P. (1998). Power and gender in the "New view" public schools. Policy Studies Journal, 26(1), 30-45. http://dx.doi.org/10.1111/j.1541-0072.1998.tb01923.x

Burns, G., \& Martin, B. N. (2010). Examination of the effectiveness of male and women educational leaders who made use of the invitational leadership style of leadership. Journal of Invitational Theory and Practice, $16,30-56$.

Chin, J. L., Lott, B., Rice, J. K., \& Sanchez-Hucles, J. (2007). Women and leadership: Transforming visions and diverse voices. Malden, MA: Blackwell Publishing. http://dx.doi.org/10.1002/9780470692332

Dorn, S. M., O’Rourke, C., \& Papalewis, R. (1996). Women in educational administration: Nine case studies. Retrieved from http://www.nationalforum.com/Electronic

Drew, G. (2010). Issues and challenges in higher education leadership: Engaging for change. The Australian Educational Researcher, 37(3), 57-76. http://dx.doi.org/10.1007/BF03216930

Hacıfazlıoglu, Ö. (2010). Entry and transition to academic leadership: Experiences of women leaders from Turkey and the U.S. Educational Sciences: Theory \& Practice, 10(4), 2257-2273.

Hill, M. S., \& Ragland, J. C. (1995). Women as educational leaders: Opening windows, pushing ceilings. Thousand Oaks, CA: Corwin Press.

Holter, A. C., \& Frabutt, J. M. (2012). Mission Driven and Data Informed Leadership. Catholic Education: A Journal of Inquiry and Practice, 15(2). Retrieved from http://digitalcommons.lmu.edu/ce/vol15/iss2/10

Hymowitz, C., \& Schellhardt, T. D. (1986). The glass ceiling: Why women can't seem to break the invisible barrier that blocks them from the top jobs. Wall Street Journal, 4(1), 4-5.

Jaber, D. F. (2005). Obstacles facing the Palestinian woman working in the public sector in the northern governorates of West Bank (Unpublished Master thesis, An-Najah National University, Nablus, Palestine).

Kamfer, F. Z. (1998). Administrative and behavioral obstacles with the women administrative leaderships in the decision-taking process: A field study on the bilateral academic institutions in Makka Mukarramah area. (Unpublished Master thesis, Kingdom of Saudi Arabia).

Lawson, J. E. (2008). Women leaders in high-poverty community schools: Work-related stress and family impact. Canadian Journal of Education, 31(1), 55-77.

Lynch, J. M. (2003). Case studies of undergraduate women's leadership development at a state university (Unpublished doctoral dissertation, Virginia Polytechnic Institute and State University, Virginia).

Mayerson, D., \& Joyce, I. (2000). A modest manifesto for shattering the glass ceiling. Harvard Business Review, Article Reprint No. R00107 Jan-Feb.

Monty, N. (2012). Women in leadership: Mentoring women into senior management. Retrieved from http://EzineArticles.com/?expert=Neen_Monty

Rue, L. W., \& Byars, L. L. (2003). Management, Skills and Application (10th ed.). Boston: McGraw-Hill. 
Sernak, K. S. (2003). Slaves no more: The caring power of African-American women leaders. Scholar-Practitioner Quarterly, 2(3), 71-97.

UNIFEM and UNICEF. (2002). The Convention on the Elimination of all forms of discrimination against women. Amman: UNIFEM Regional Office for the Arabic States) and UNICEF (Regional Office for the Middle East and North Africa.

Walter, G., \& Mimi, W. (2002). An investigation of dean leadership. New Orleans: American Educational Research Association.

White, K. (2012). The gendered shaping of university leadership in Australia, South Africa and the United $\begin{array}{llll}\text { Kingdom. Higher } & \text { 293-307. }\end{array}$ http://dx.doi.org/10.1111/j.1468-2273.2012.00523.x

Wilkinson, J. (2009). A tale of two women leaders: Diversity policies and practices in enterprise universities. The Australian Educational Researcher, 36(2), 39-54. http://dx.doi.org/10.1007/BF03216898

Yang, N. (1998). An international perspective on socioeconomic changes and their effects on life stress and career success of working women. SAM Advanced Management Journal, 63(3), 15-21.

Yukl, G. A. (2002). Leadership in organization (5th ed.). New Jersey: Prentice Hall.

Zanville, R. L. (2001). A quantitative analysis of the personal characteristics and workplace experiences of women and men as professional and community leaders. International Business and Career Community News, Networking \& Strategy for Women. Retrieved from http://www.advancingwomen.com/awl/winter2001/zanville/zanville.html

Zulu, C. B. (2011). Women leaders' construction of leadership and management of the academic department. South African Journal of Higher Education, 25(4), 838-852.

\section{Appendix}

Questionnaire

Challenges facing the women's academic leaderships in the secondary schools of Irbid educational area.

Her Kindness: Principal/Assistant Principal

Peace and Blessings of Allah be upon you.

The researcher is conducting a scientific study about the challenges facing the women's academic leaderships in the secondary schools of Irbid Educational Area. For this purpose, a questionnaire had been constructed comprising (41) items distributed over the following domains: Organizational, Personal, Social and Physical Challenges.

The researches highly appreciates your kindness to carefully read the items and respond to them by ticking $(\sqrt{ })$ in front of the item you find suitable and best expressing your point of view about the prevalence degree of the challenge. Assuring you that your responses will be used for the scientific research purposes exclusively.

Best Regards and Gratitude.

Table A1. Illustrative response sample

\begin{tabular}{lllllll}
\hline No. & Items & \multicolumn{3}{l}{ Evaluation Degree } \\
\cline { 3 - 7 } & & Very & High & Medium & Low & Very \\
& & High & $(4)$ & $(3)$ & $(2)$ & Low \\
& & $(5)$ & & & & $(1)$ \\
\hline 1 & Difficulty in controlling certain employees & $\sqrt{ }$ & & & \\
2 & Conflict in some circulars directed at work & & & $\sqrt{ }$ & \\
\hline
\end{tabular}

First: General Information

Job Title: Principal ( ) Assistant Principal ( )

Academic Degree: MA or Higher ( ) BA ( ) 
Years of Experience:Less than 5 Years ( ) 5-10 years ( ) more than 10 Years ( )

Second: Domains and Items of the Questionnaire

Table A2. First domain: Organizational challenges facing the women's academic leaderships in the secondary schools

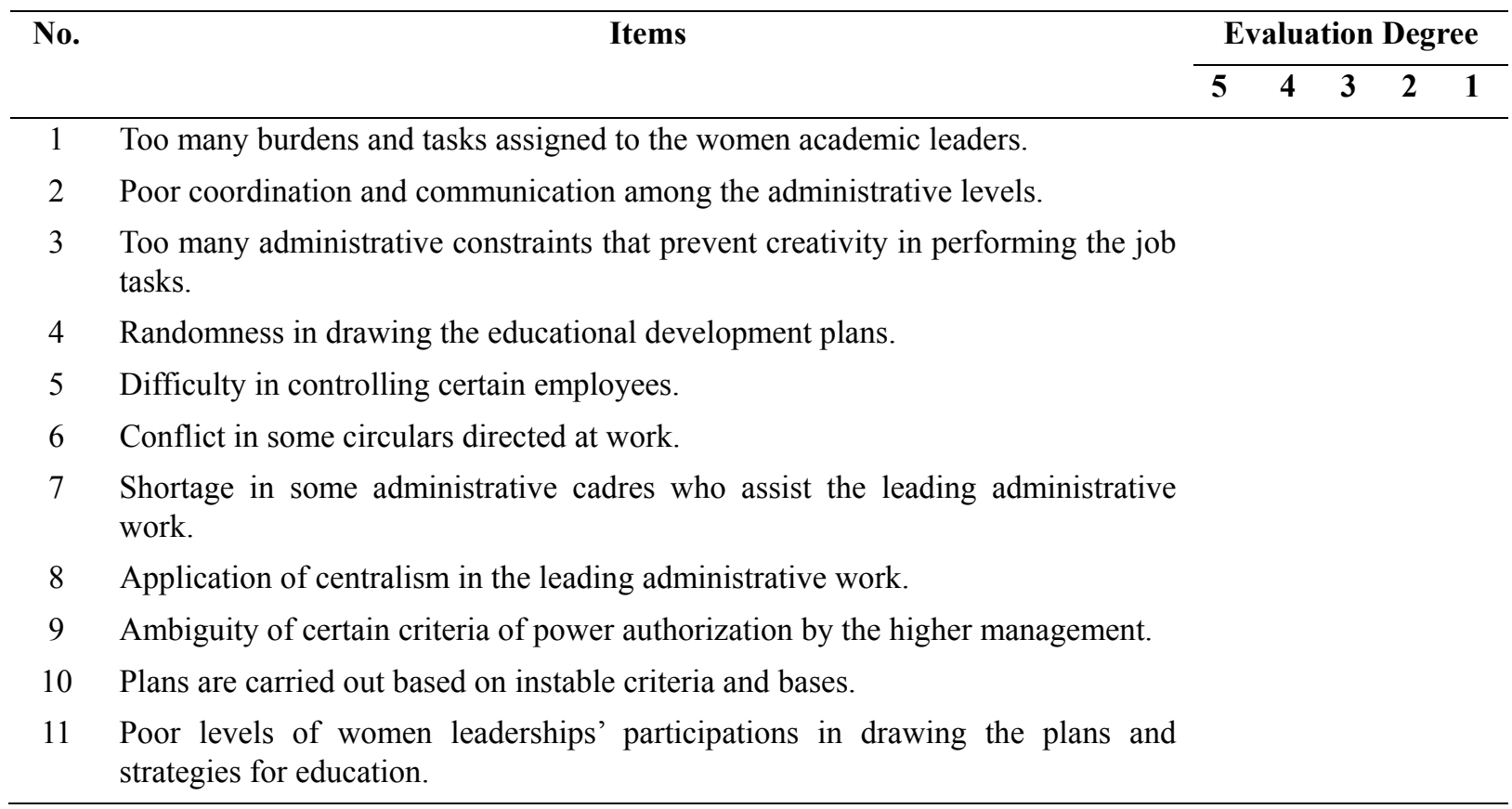

Table A3. Second domain: Personal challenges facing the women's academic leaderships in the secondary schools

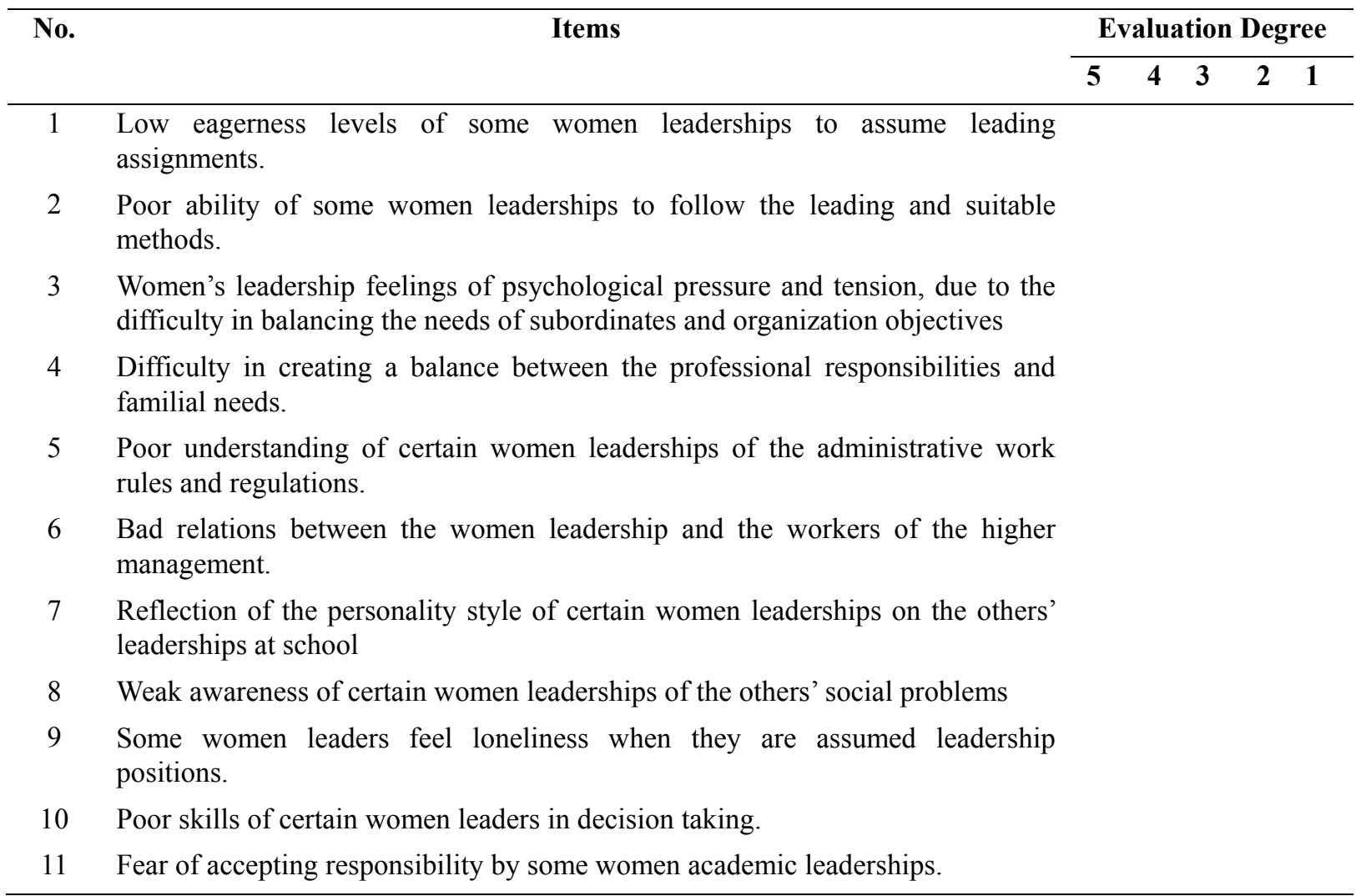


Table A4. Third domain: Social challenges facing the women's academic leaderships in the secondary schools

\begin{tabular}{|c|c|c|c|c|c|c|}
\hline \multirow[t]{2}{*}{ No. } & \multirow[t]{2}{*}{ Items } & \multicolumn{5}{|c|}{ Evaluation Degree } \\
\hline & & 5 & 4 & 3 & 2 & 1 \\
\hline 1 & Community negative view of the woman assumed leadership positions. & & & & & \\
\hline 2 & $\begin{array}{l}\text { Difficulty of dealings by certain women leaders with male colleagues and heads } \\
\text { of departments. }\end{array}$ & & & & & \\
\hline 3 & $\begin{array}{l}\text { Dominance of the belief that the right role of the woman is in her family not in } \\
\text { community leaderships }\end{array}$ & & & & & \\
\hline 4 & Poor confidence of the higher management in some women leaders. & & & & & \\
\hline 5 & Prevailing belief that the woman has poor abilities and skills as a leader. & & & & & \\
\hline 6 & $\begin{array}{l}\text { Low acceptability levels of the woman's authority by the womens working with } \\
\text { her. }\end{array}$ & & & & & \\
\hline 7 & $\begin{array}{l}\text { Prevalence of the traditional, informal relation rather than the professional } \\
\text { relation between the women leader and her subordinates. }\end{array}$ & & & & & \\
\hline 8 & $\begin{array}{l}\text { Poor professional culture with some women subordinates about the academic } \\
\text { leadership work. }\end{array}$ & & & & & \\
\hline
\end{tabular}

Table A5. Fourth domain: Physical challenges facing the women's academic leaderships in the secondary schools

\begin{tabular}{|c|c|c|c|c|c|c|}
\hline \multirow[t]{2}{*}{ No. } & \multirow[t]{2}{*}{ Items } & \multicolumn{5}{|c|}{ Evaluation Degree } \\
\hline & & 5 & 4 & 3 & 2 & 1 \\
\hline 1 & Lack of physical incentives for the women leaders. & & & & & \\
\hline 2 & $\begin{array}{l}\text { Scarcity of external spaces and places suitable for practicing extracurricular } \\
\text { activities at school. }\end{array}$ & & & & & \\
\hline 3 & Areas of the buildings are insufficient for the educational requirements. & & & & & \\
\hline 4 & Negligence of providing an internet that serves the academic work. & & & & & \\
\hline 5 & Rarity of suitable laboratories and learning resources at schools. & & & & & \\
\hline 6 & Poor security and safety measurements at the educational buildings & & & & & \\
\hline 7 & $\begin{array}{l}\text { Weakness of the incentive system that encourages the school staff to carry out } \\
\text { scientific studies. }\end{array}$ & & & & & \\
\hline 8 & $\begin{array}{l}\text { Rarity of material incentives provided for the talented and creative women } \\
\text { students. }\end{array}$ & & & & & \\
\hline 9 & Rarity of modern, suitable technologies at school. & & & & & \\
\hline 10 & $\begin{array}{l}\text { Poor maintenance services of he technical appliances and buildings of the } \\
\text { schools. }\end{array}$ & & & & & \\
\hline 11 & Rarity of required supplies for school teaching. & & & & & \\
\hline
\end{tabular}

\section{Copyrights}

Copyright for this article is retained by the author(s), with first publication rights granted to the journal.

This is an open-access article distributed under the terms and conditions of the Creative Commons Attribution license (http://creativecommons.org/licenses/by/3.0/). 